\title{
Métodos de Isolamento de Bactérias do Filoplano de Tomateiro Visando Populações Específicas e Implicações como Agentes de Biocontrole*
}

\author{
Bernardo A. Halfeld-Vieira ${ }^{1,2}$, Reginaldo S. Romeiro ${ }^{1}$ \& Eduardo S.G. Mizubuti ${ }^{1}$ \\ ${ }^{1}$ Universidade Federal de Viçosa, Departamento de Fitopatologia, CEP 36570-000, Viçosa, MG, fax (31) 3899-2240, \\ e-mail: rromeiro@ufv.br; ${ }^{2}$ Endereço atual: Embrapa Roraima, BR 174, km 08, Cx. Postal 133, CEP 69301-970, \\ Boa Vista, RR, fax (95) 626-7125, e-mail: halfeld@cpafrr.embrapa.br
}

(Aceito para publicação em 16/09/2004)

Autor para correspondência: Bernardo A. Halfeld-Vieira

HALFELD-VIEIRA, B.A., ROMEIRO, R.S. \& MIZUBUTI, E.S.G. Métodos de isolamento de bactérias do filoplano de tomateiro visando populações específicas e implicações como agentes de biocontrole. Fitopatologia Brasileira 29:638-643. 2004.

\section{RESUMO}

Em um processo de seleção de bactérias do filoplano de tomateiro (Lycopersicon esculentum) com potencial para o controle de doenças da parte aérea da cultura, diferentes métodos de isolamento foram utilizados visando obter isolados da população total, da população da superfície foliar e isolados que habitam locais protegidos do filoplano e/ou que toleram fatores de estresse. Foi testada a capacidade de 300 isolados em controlar in vivo, as doenças causadas por Alternaria solani, Pseudomonas syringae pv. tomato e Phytophthora infestans. Os testes foram repetidos para cada um dos antagonistas selecionados, estudando-se, também, a capacidade de controlar a mancha-bacteriana, causada por Xanthomonas vesicatoria. Os resultados demonstraram haver predomínio de antagonistas provenientes de folíolos do terço superior da planta de população total ou da superfície. Entretanto, o único antagonista selecionado, isolado de folíolos do terço inferior, foi obtido de locais protegidos do filoplano e/ou capaz de tolerar fatores de estresse.

Palavras-chave adicionais: Lycopersicon esculentum, controle biológico, residentes do filoplano.

\section{ABSTRACT}

Isolation methods of tomato phylloplane bacteria aiming specific populations and implications as biocontrol agents

In a process of selecting tomato (Lycopersicon esculentum) phylloplane bacteria with potential for controlling aerial diseases of this crop, different isolation methods were used to obtain the isolates from total leaf surface and also from protected sites of the phylloplane. Three hundred isolates were tested in vivo for their ability to control diseases caused by Alternaria solani, Pseudomonas syringae pv. tomato and Phytophthora infestans. The results demonstrated a predominance of antagonists in the total population originating on the surface of the leaflets harvested from the upper leaves of the plants. Only one selected antagonistic isolate obtained from the lower leaves was recovered from the protected sites of the phylloplane and/or was stress tolerant.

\section{INTRODUÇÃO}

Dentre os diversos agentes bióticos que podem ser utilizados em controle biológico, as bactérias do filoplano são uma alternativa ainda pouco explorada, principalmente quando comparadas às rizobactérias (Lindow \& Leveau, 2002) e esta diferença se deve, em grande parte, às características do habitat onde cada um se encontra. A filosfera (Last, 1955; Ruinen, 1956) é um ambiente complexo que sofre variações intermitentes de umidade, temperatura, incidência de radiação, ventilação, composição e quantidade de nutrientes disponíveis (Andrews \& Hirano, 1991; Wilson et al., 1999), o que dificulta o estabelecimento de populações no filoplano. Estes fatores fazem com que, muitas vezes, agentes de biocontrole promissores sejam ineficientes, por serem incapazes de sobreviver ou manter suas populações em alta densidade, o que os impede de exercer suas funções no controle

\footnotetext{
*Parte da Tese de Doutorado do primeiro autor, Universidade Federal de
} Viçosa (2002). Apoio Financeiro: FAPEMIG de doenças (Leben, 1985).

Desta forma, obter antagonistas com maior capacidade de sobrevivência, pode ser um fator que determine sua efetividade em condições de campo. As bactérias do filoplano utilizam basicamente dois tipos de estratégias para sobreviverem em ambientes de estresse, de tolerância e de escape. A primeira requer capacidade em tolerar condições inóspitas, tais como a incidência de radiação ultravioleta, baixa umidade, além de outros, enquanto a segunda, considera a habilidade da bactéria em explorar sítios que ofereçam um ambiente menos sujeito a estresses ambientais (Andrews \& Hirano, 1991; Beattie \& Lindow, 1995; Beattie \& Lindow, 1999; Wilson et al., 1999). Explorar essas propriedades pode ser um modo de otimizar a obtenção de bons agentes de biocontrole.

Além da questão da sobrevivência, um outro fator que pode ser essencial para que um antagonista seja eficaz é o seu estabelecimento no mesmo local que o patógeno, desenvolvendo-se nas mesmas condições ambientais ideais 
para a ocorrência da doença. Assim, um processo de seleção de antagonistas visando o controle da pinta-preta, causada por Alternaria solani Sorauer, poderia ser mais eficiente utilizando antagonistas que habitem folíolos mais velhos, já que nestes locais o patógeno se desenvolve melhor e apresenta período de incubação mais curto do que em folíolos jovens (Rotem, 1994). Da mesma forma, pode-se fazer uma analogia à capacidade do antagonista se desenvolver rapidamente em faixas de temperatura ideais para cada patógeno desafiante. Alternaria solani e Pseudomonas syringae pv. tomato (Okabe 1933) Young, Dye \& Wilkie 1978, por exemplo, têm como temperatura ótima de desenvolvimento $25^{\circ} \mathrm{C}$ (Rotem, 1994; Preston, 2000); já Phytophthora infestans (Mont.) de Bary se desenvolve muito bem em uma faixa de temperatura próxima a $18{ }^{\circ} \mathrm{C}$ (Erwin \& Ribeiro, 1996).

Este trabalho teve como objetivo obter antagonistas com capacidade de controle das doenças causadas por $A$. solani, $P$. infestans e $P$. syringae pv. tomato, em condições de casa de vegetação, a partir de 300 isolados bacterianos obtidos do filoplano de tomateiro (Lycopersicon esculentum Mill.), testando-se também, posteriormente, sua eficiência contra Xanthomonas vesicatoria (ex Doidge 1920) Vauterin, Hoste, Kersters \& Swings 1995.

Por meio de metodologias distintas, investigou-se a possibilidade de haver relação entre os critérios de isolamento de cada antagonista, com os locais habitados naturalmente por eles e sua capacidade de sobrevivência no filoplano, além de se associarem características específicas da biologia de cada antagonista e dos patógenos desafiantes.

\section{MATERIAL E MÉTODOS}

\section{Coleta dos folíolos}

As amostras foram coletadas em diferentes épocas e locais, de plantas de tomateiro não submetidas à pulverização com produtos químicos, em plantios caseiros na cidade de Viçosa-MG. Retiraram-se folíolos ao acaso no terço superior (S) e inferior (I) da planta. Os folíolos foram acondicionados em sacos de papel e identificados de acordo com o local da planta do qual foram retirados.

\section{Isolamento dos potenciais candidatos a antagonistas}

Isolados dos candidatos a antagonistas foram obtidos de três formas distintas. Visando obter amostras da população total de bactérias do filoplano (T), dois folíolos foram depositados em Erlenmeyer de $150 \mathrm{ml}$ de capacidade, contendo $50 \mathrm{ml}$ de solução salina $(0,85 \% \mathrm{NaCl})$ estéril com $0,3 \%$ de Tween 80 (Romeiro, 2001) e submetidos à ultrasom a $60 \mathrm{~Hz}$ por $20 \mathrm{~min}$. Para isolamento de bactérias da população da superfície foliar (L), foram pipetados $3 \mathrm{ml}$ de solução salina estéril com $0,3 \%$ de Tween 80 com pipeta automática, deixando-se escorrer esta alíquota sobre cada folíolo obtendo-se um extrato pela lavagem de dois folíolos por amostra. Já para obtenção de isolados que habitam locais protegidos do filoplano e/ou que toleram fatores de estresse (E), dois folíolos permaneceram por $30 \mathrm{~s}$ em solução de hipoclorito de sódio a $0,5 \%$ sendo em seguida lavados rapidamente em água estéril (adaptado de Schneider \& Grogan, 1977) e submetidos à ultra-som a $60 \mathrm{~Hz}$ por $20 \mathrm{~min}$, nas mesmas condições para obtenção de amostras da população total.

Para cada extrato foi feita uma diluição seriada, em fator de diluição variando até 1:5.000, sendo depositados 100 $\mu l$ das amostras obtidas em cada diluição, em duas placas de Petri contendo meio de cultura 523 (Kado \& Heskett, 1970) espalhando-se com alça de Drigalski sobre a superfície para o semeio (Romeiro, 2001). Uma das placas semeadas com a mesma amostra foi levada à incubadora a $25^{\circ} \mathrm{C}(\mathrm{A})$ e outra a $18{ }^{\circ} \mathrm{C}(\mathrm{B})$.

As culturas puras foram obtidas de placas cujo fator de diluição permitiu o crescimento de colônias isoladas. Estas foram transferidas para tubos de ensaio contendo meio de cultura 523 (Kado \& Heskett, 1970), coletando-se preferencialmente colônias morfologicamente distintas (Berg et al., 2002). Um total de 300 isolados bacterianos foi obtido nesta etapa.

\section{Seleção massal}

Para seleção massal dos melhores antagonistas, foram utilizadas plantas de tomateiro cv. Kada com cinco folhas desenvolvidas, contidas em vasos independentes, com capacidade para $500 \mathrm{ml}$. Cada grupo de seis plantas foi pulverizado com uma suspensão ajustada em absorbância a $540 \mathrm{~nm}\left(\mathrm{~A}_{540}\right)$ igual a 0,3 de um dos candidatos a antagonistas a ser testado, utilizando-se como tratamentos controle para A. solani e $P$. infestans três plantas pulverizadas com clorotalonil $\left(1,5\right.$ g i.a. $\left.^{-1}\right)$ e para $P$. syringae pv. tomato três plantas com oxicloreto de cobre $\left(1,7\right.$ g i.a. $\left.1^{-1}\right)$. A testemunha consistiu de seis plantas pulverizadas com água.

Após quatro dias em casa de vegetação, folíolos das plantas pulverizadas com as bactérias em teste e com clorotalonil foram retirados e depositados em três caixas gerbox contendo papel toalha umedecido, em uma quantidade suficiente para cobrir toda a superfície interna das caixas. Três plantas foram pulverizadas com uma suspensão de conídios de $A$. solani $\left(2,5 \times 10^{3}\right.$ conídios $\left.\mathrm{ml}^{-1}\right)$ e outras três com suspensão de células de $P$. s. pv. tomato $\left(\mathrm{A}_{540}=0,15\right)$, levando-se para câmara úmida por $24 \mathrm{~h}$ a $25^{\circ} \mathrm{C}$, constituindo cada planta uma repetição. Os folíolos depositados em gerbox foram borrifados com $2,5 \times 10^{3}$ cistos $\mathrm{ml}^{-1}$ de $P$. infestans. Cinco lâminas de microscopia foram distribuídas entre as caixas para se determinar, por microscopia, o número de cistos por área pulverizada. $\mathrm{O}$ material foi mantido em câmara de crescimento a $18^{\circ} \mathrm{C}$ com fotoperíodo de $12 \mathrm{~h}$.

Ao se observar os primeiros sintomas, quantificou-se o número de lesões/folíolo para $A$. solani e $P$. syringae pv. tomato. Para $P$. infestans, foi determinada a freqüência de infecção calculando-se a porcentagem de lesões nos folíolos contidos na área interna das gerbox em relação ao número de cistos depositados, determinado no momento da inoculação. A severidade da doença três dias após o aparecimento dos sintomas também foi quantificada, uma vez 
que, em alguns casos, houve esporulação do patógeno sem serem observadas manchas nos folíolos. A avaliação foi feita comparando-se a área foliar sadia dos tratamentos com cada antagonista e os folíolos tratados com clorotalonil.

Testou-se um total de 300 isolados bacterianos para cada um dos patógenos, em seis ciclos de seleção, utilizandose cinqüenta isolados por ciclo.

O critério de seleção adotado preconizou que os antagonistas que proporcionavam menor severidade de doença, com menor valor de desvio padrão, para pelo menos dois patógenos, fossem selecionados em cada etapa.

Dos 300 isolados bacterianos testados para cada patógeno, um total de dez antagonistas foi preliminarmente selecionado.

\section{Determinação dos melhores antagonistas selecionados}

Para escolha dos antagonistas mais promissores dentre os dez provenientes da seleção massal, o mesmo procedimento foi adotado, testando-se também $X$. vesicatoria como patógeno desafiante, da mesma forma que os ensaios para $P$. syringae pv. tomato. Entretanto, foram utilizadas cinco repetições para cada tratamento, onde cada repetição foi representada por duas plantas de tomateiro cv. Santa Clara, com cinco folhas desenvolvidas, cultivadas em vasos independentes.

Nesta etapa foram selecionados os quatro antagonistas com eficiência contra o maior número de patógenos desafiantes, por meio dos mesmos critérios de avaliação utilizados na etapa de seleção massal.

\section{Confirmação da efetividade dos antagonistas}

Em etapa posterior de confirmação da efetividade dos quatro melhores antagonistas, foram utilizadas quatro repetições para cada tratamento, utilizando-se a mesma metodologia adotada nos ensaios anteriores, porém utilizandose plantas de tomateiro da cv. Kada. Os patógenos desafiantes utilizados nesta etapa foram A. solani, P. syringae pv. tomato e $X$. vesicatoria .

\section{Análise de dados}

A análise estatística dos ensaios foi realizada por meio do programa SAS, versão 8.00, utilizando o Proc GLM e teste de Tukey a $5 \%$.

\section{RESULTADOS E DISCUSSÃO}

Os procedimentos para isolamento permitiram obter diferentes números de unidades formadoras de colônias. Nos métodos $\mathrm{T}$ e L, somente nas culturas provenientes do extrato submetido a diluição em fator 1:5.000 foram observadas colônias isoladas, enquanto no método E observaram-se colônias apenas no extrato não diluído, em número bastante reduzido. Estas observações indicam que a probabilidade de se obter bactérias provenientes de populações que habitam sítios protegidos ou que toleram fatores de estresse, pelos métodos T e L é muito pequena, já que sua representatividade na população total foi menor. Verificou-se também menor número de colônias de culturas das mesmas amostras incubadas a $18{ }^{\circ} \mathrm{C}$, que as incubadas a $25^{\circ} \mathrm{C}$. Houve também um maior atraso para o seu surgimento, como esperado.

Das 300 bactérias testadas para cada patógeno desafiante em seis ciclos de seleção massal, um total de dez antagonistas foi selecionado (Tabela 1). Não foi observada tendência relacionando o método de isolamento utilizado com características biológicas específicas dos patógenos desafiantes. Entretanto, os resultados indicam haver predomínio de antagonistas obtidos a partir de folíolos do terço superior da planta, de população total ou da superfície, com exceção do antagonista UFV-IEA 6, obtido de folíolos do terço inferior após desinfestação dos folíolos.

É possível que organismos isolados por este proce-

TABELA 1 - Antagonistas selecionados em diferentes ciclos de seleção massal, que apresentaram controle satisfatório para pelo menos duas doenças em plantas de tomateiro (Lycopersicon esculentum) cv. Kada

\begin{tabular}{lcl}
\hline Antagonista & $\begin{array}{c}\text { Ciclo em que foi } \\
\text { selecionado }\end{array}$ & Doença controlada \\
\hline UFV-SLA 6* & $1^{\circ}$ ciclo & Pinta-preta e Requeima \\
UFV-STB 6 & $2^{\circ}$ cido & Pinta-preta e Requeima \\
UFV-STA 33 & $2^{\circ}$ ciclo & Mancha-bacteriana pequena e Requeima \\
UFV-IEA 6 & $3^{\circ}$ ciclo & Mancha-bacteriana pequena e Requeima \\
UFV-STB 2 & $4^{\circ}$ ciclo & Pinta-preta e Requeima \\
UFV-STB 30 & $4^{\circ}$ ciclo & Pinta-preta e Mancha-bacteriana pequena \\
UFV-STB 70 & $5^{\circ}$ ciclo & Pinta-preta e Requeima \\
UFV-STB 72 & $5^{\circ}$ ciclo & Pinta-preta e Requeima \\
UFV-SLA 80 & $6^{\circ}$ ciclo & Pinta-preta e Mancha-bacteriana pequena \\
UFV-STB 78 & $6^{\circ}$ ciclo & Pinta-preta e Requeima \\
\hline
\end{tabular}

\footnotetext{
* As três letras que distinguem os antagonistas significam: S, isolado obtido do terço superior; I, isolado obtido do terço inferior; T, isolado da população total de bactérias do filoplano; L, isolado da população da superfície foliar; E, isolados que habitam locais protegidos do filoplano e/ou que toleram fatores de estresse; A, incubação a $25^{\circ} \mathrm{C}$ e $\mathrm{B}$, incubação a
} $18^{\circ} \mathrm{C}$. A numeração é aleatória, conforme isolamento. 
dimento se aproveitem de vantagens como tolerar as adversidades ambientais ou colonizar os sítios protegidos, uma vez que nestes locais ocorre grande competição entre microrganismos, que procuram um ambiente com maior estabilidade (Schneider \& Grogan, 1977; Leben, 1988). Além disso, dois fatores oferecem vantagens na colonização destes sítios: uma maior capacidade de sobrevivência por serem locais menos sujeitos a estresses ambientais (Beattie \& Lindow, 1995; Beattie \& Lindow, 1999; Wilson et al., 1999) e o acesso a nutrientes pouco disponíveis (Andrews \& Hirano, 1991). Mercier \& Lindow (2000) demonstraram que, embora a disponibilidade de fontes de carbono em folíolos de tomateiro seja bastante abundante e capaz de suprir grandes populações bacterianas, em relação a outras plantas como ervilha (Pisum sativum L.) e milho (Zea mays L.), uma quantidade significativa não é capaz de ser utilizada, devido ao difícil acesso a esses nutrientes, fazendo com que a competição nesses locais seja reduzida.

Os resultados demonstram que todos os dez antagonistas selecionados foram capazes de reduzir a severidade para os patógenos desafiantes em tomate cv. Santa Clara. O isolado UFV-IEA 6 foi o que apresentou melhores resultados, reduzindo significativamente a severidade da doença, para todos os patógenos (Figuras 1-4). Percebe-se que, na maioria dos casos, há maior eficiência de controle para as doenças que o antagonista foi selecionado (Tabela 1).

Nestes ensaios também foi verificado que UFV-SLA 80 se destacou no controle da pinta-preta ( $A$. solani) e requeima ( $P$. infestans), UFV-STB 2 no controle da pintapreta e da mancha-bacteriana pequena ( $P$. syringae pv. tomato) e UFV-STB 6 no controle da pinta-preta, requeima e manchabacteriana pequena. Por estes resultados, estes isolados foram também selecionados entre os dez melhores, para serem re-

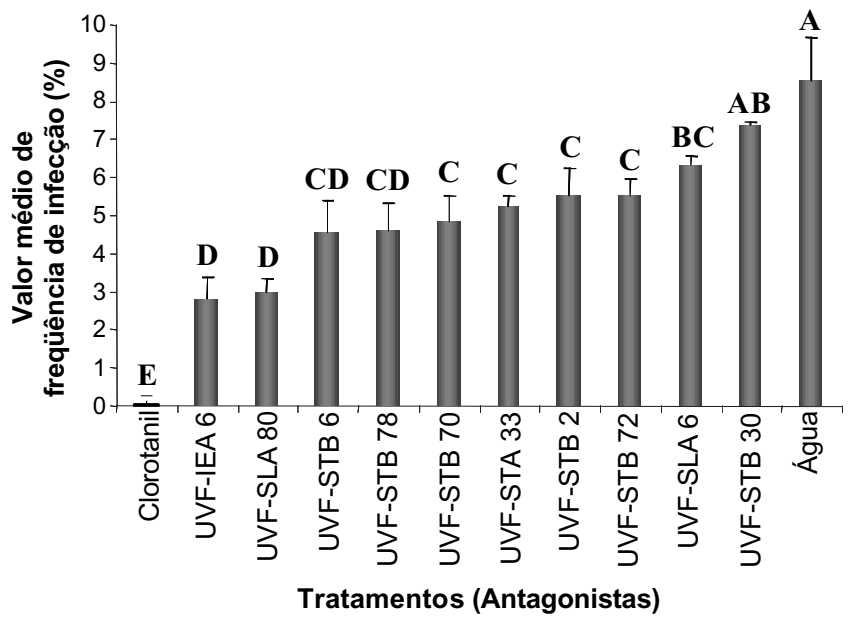

FIG. 1 - Valores médios da freqüência de infecção de Phytophthora infestans em folíolos de tomateiro (Lycopersicon esculentum) cv. Santa Clara, tratados com diferentes antagonistas. Médias seguidas da mesma letra não diferem entre si pelo teste de Tukey a 5\%. Os valores apresentados correspondem às médias e as barras representam o desvio padrão.

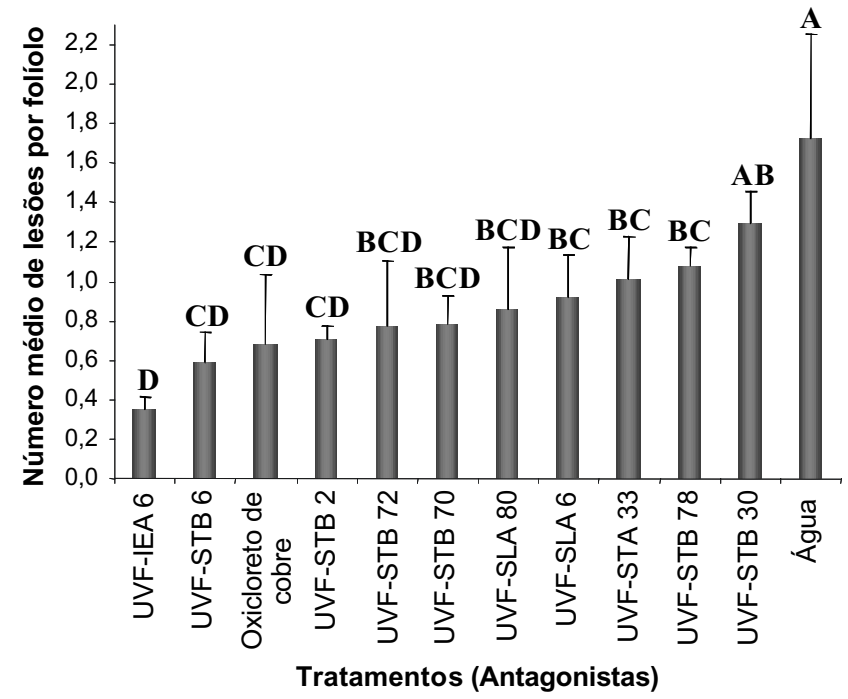

FIG. 2 - Número médio de lesões por folíolo causadas por Pseudomonas syringae pv. tomato em tomateiro (Lycopersicon esculentum) cv. Santa Clara, tratados com diferentes antagonistas. Médias seguidas da mesma letra não diferem entre si pelo teste de Tukey a $5 \%$. Os valores apresentados correspondem às médias e as barras representam o desvio padrão.

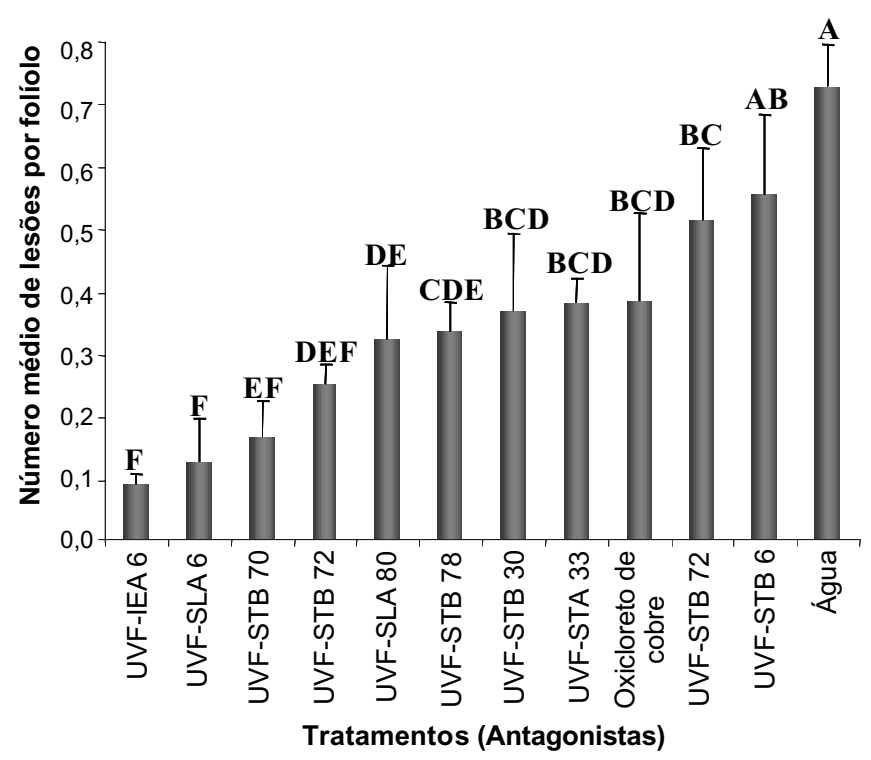

FIG. 3 - Número médio de lesões por folíolo causadas por Xanthomonas vesicatoria em tomateiro (Lycopersicon esculentum) cv. Santa Clara, tratados com diferentes antagonistas. Médias seguidas da mesma letra não diferem entre si pelo teste de Tukey a $5 \%$. Os valores apresentados correspondem às médias e as barras representam o desvio padrão.

testados.

Em etapa seguinte de confirmação dos resultados, repetiram-se os testes em plantas de tomate cv. Kada, utilizando-se os quatro antagonistas selecionados na etapa anterior. Verificou-se mais uma vez que todos foram capazes 


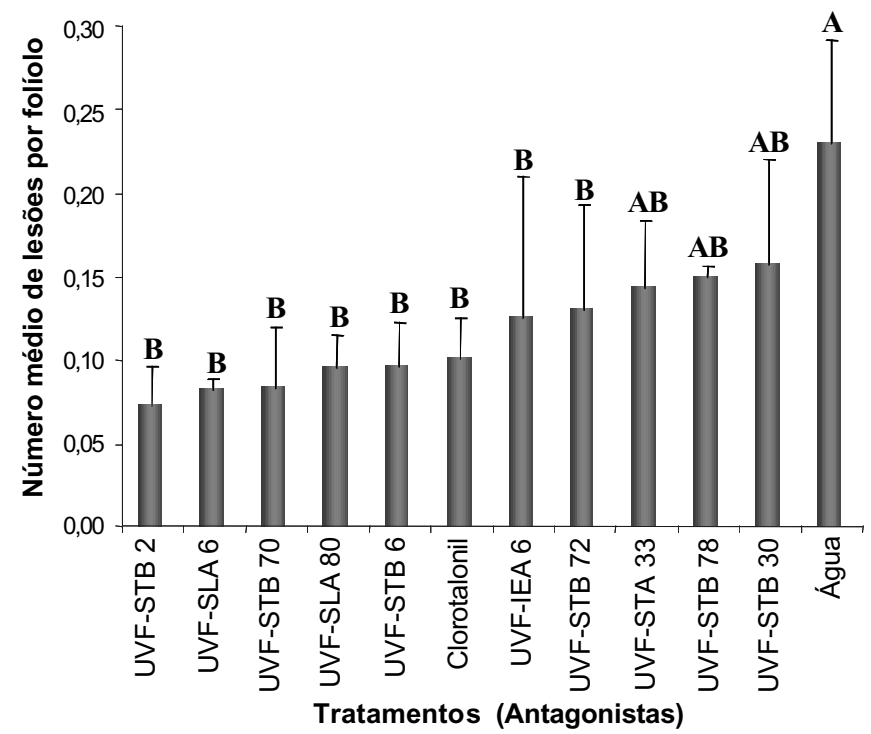

FIG. 4 - Número médio de lesões por folíolo causadas por Alternaria solani em tomateiro (Lycopersicon esculentum) cv. Santa Clara, tratados com diferentes antagonistas. Médias seguidas da mesma letra não diferem entre si pelo teste de Tukey a $5 \%$. Os valores apresentados correspondem às médias e as barras representam o desvio padrão.

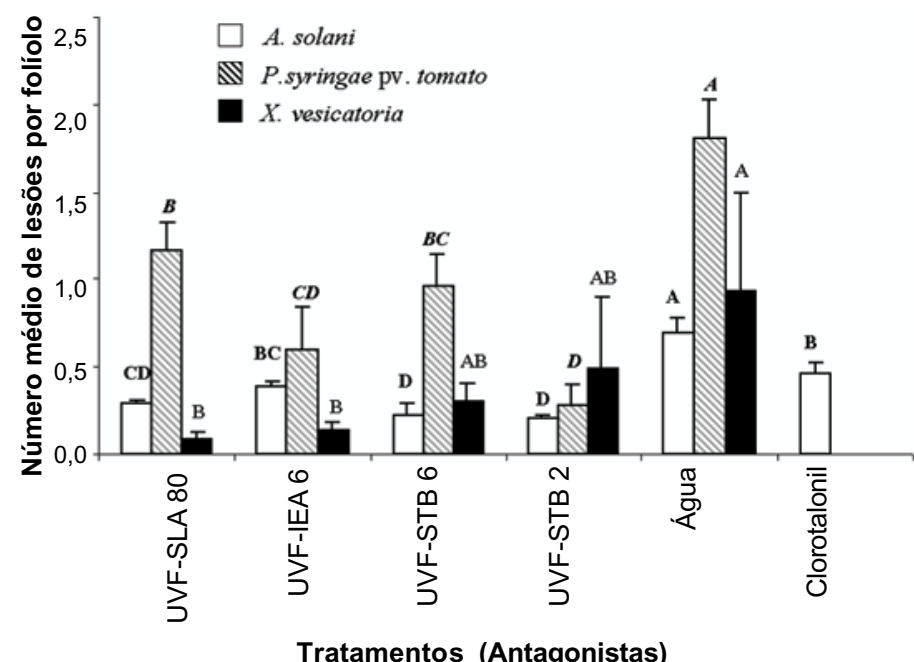

FIG. 5 - Número médio de lesões por folíolo causadas por Alternaria solani, Pseudomonas syringae pv. tomato e Xanthomonas vesicatoria, em tomateiro (Lycopersicon esculentum) cv. Kada, tratados com diferentes antagonistas. Médias seguidas da mesma letra não diferem entre si pelo teste de Tukey a 5\%. Os valores apresentados correspondem às médias e as barras representam o desvio padrão.

de reduzir o número de lesões por folíolo, para os patógenos A. solani, P. syringae pv. tomato e $X$. vesicatoria (Figura 5), e que o isolado UFV-IEA 6 se destaca novamente no controle da mancha-bacteriana pequena e mancha-bacteriana $(X$. vesicatoria); UFV-STB 2 para pinta-preta e mancha- bacteriana pequena e UFV-STB 6 para pinta-preta, com eficiência intermediária em relação aos demais patógenos desafiantes, enquanto que UFV-SLA 80 obteve bons resultados no controle da pinta-preta e mancha-bacteriana.

Os dados apresentados demonstram que os quatro antagonistas têm um grande potencial para uso como agentes de biocontrole das doenças para os quais foram selecionados, e que, o isolado UFV-IEA 6, se mantém eficiente tanto em plantas de tomate pertencentes a cv. Kada quanto a cv. Santa Clara.

O fato dos antagonistas serem capazes de controlar uma ampla gama de doenças de origem fúngica e bacteriana, faz com que seja importante a determinação do(s) mecanismo(s) responsável(is) pela sua eficiência, uma vez que podem estar envolvidos antibiose, parasitismo, competição por nutrientes ou até a indução de resistência, já que a inespecificidade de controle contra doenças causadas por diversos organismos é uma das características deste mecanismo de ação (van Loon et al., 1998).

\section{REFERÊNCIAS BIBLIOGRÁFICAS}

ANDREWS, J.H. \& HIRANO, S.S. (Eds.) Microbial Ecology of Leaves. New York. Springer-Verlag. 1991.

BEATTIE, G.A. \& LINDOW, S.E. The secret life of foliar bacterial pathogens on leaves. Annual Review of Phytopathology 33:145-172. 1995.

BEATTIE, G.A. \& LINDOW, S.E. Bacterial colonization of leaves:a spectrum of strategies. Phytopathology 89:353-359. 1999.

BERG, G., ROSKOT, N., STEIDLE, A., EBERL, L., ZOCK, A. \& SMALLA, K. Plant-dependent genotypic and phenotypic diversity of antagonistic rhizobacteria isolated from different Verticillium host plants. Applied and Environmental Microbiology 68:3328-3338. 2002.

ERWIN, D.C. \& RIBEIRO, O.K. Phytophthora Diseases Worldwide. St. Paul. APS Press. 1996.

KADO, C.I. \& HESKETT, M.G. Selective media for isolation of Agrobacterium, Corynebacterium, Erwinia, Pseudomonas and Xanthomonas. Phytopathology 60:969-976. 1970.

LAST, F.T. Seazonal incidence of Sporobolomyces on cereal leaves Transactions of the British Mycological Society. 38:221-239. 1955. LEBEN, C., Introductory remarks:Biological control strategies in the phylloplane. In:Windels, C.E. \& Lindow, S.E. (Eds.) Biological control on the phylloplane. St. Paul. APS Press. 1985. pp.1-5.

LEBEN, C. Relative humidity and the survival of epiphytic bacteria with buds and leaves of cucumber plants. Phytopathology 78:179185. 1988.

LINDOW, S.E. \& LEVEAU, J.H.J. Phyllosphere microbiology. Current Opinion in Biotechnology 13:238-243. 2002.

MERCIER, J. \& LINDOW, S.E. Role of leaf surface sugars in colonization of plants by bacterial epiphytes. Applied and Environmental Microbiology 66:369-374. 2000.

PRESTON, G.M. Pseudomonas syringae pv. tomato:the right pathogen, of the right plant, at the right time. Molecular Plant Pathology 1:263-275. 2000. 
Comparação entre diferentes métodos de isolamento de bactérias do ...

ROMEIRO, R.S. Métodos em Bacteriologia de Plantas. Viçosa. UFV. 2001.

ROTEM, J. The Genus Alternaria: biology, epidemiology and pathogenicity. St. Paul. APS Press. 1994.

RUINEN, J. Occurrence of Beijerinckia species in the phyllosphere. Nature 177:220-221. 1956.

SCHNEIDER, R.W. \& GROGAN, R.G. Tomato leaf trichomes, a habitat for resident populations of Pseudomonas tomato.
Phytopathology 67:898-902. 1977.

VAN LOON, L.C., BAKKER, P.A.H.M. \& PIETERSE, C.M.J. Systemic resistance induced by rhizosphere bacteria. Annual Review of Phytopathology 36:453-483. 1998.

WILSON, M., HIRANO, S.S. \& LINDOW, S.E. Location and survival of leaf-associated bacteria in relation to pathogenicity and potential for growth within the leaf. Applied and Environmental Microbiology 65:1435-1443. 1999. 